\title{
Bullying Behavior does not Support the Normal Standard of Care
}

\author{
Yarbrough $\mathrm{JR}^{1^{*}}$ and Davis $\mathrm{LA}^{2}$ \\ ${ }^{1}$ Clinical Assistant \& Virginia Engler Professor of Business Management, West Texas A\&M University, United States \\ ${ }^{2}$ Associate Department Head, Graduate Nursing Program, West Texas A\&M University, United States
}

${ }^{*}$ Corresponding author: Yarbrough JR, Clinical Assistant \& Virginia Engler Professor of Business Management, West Texas A\&M University, United States, Tel: 864-285-6670, E-mail: jryarbrough@mail.wtamu.edu

Citation: Yarbrough JR, Davis LA (2019) Bullying Behavior Does Not Support the Normal Standard of Care. J Nurs Healthcare Manage 2: 101

Article history: Received: 04 November 2018, Accepted: 16 January 2019, Published: 18 January 2019

\begin{abstract}
According to the Bureau of Labor Statistics there were 2,955,200 nursing jobs in 2016 and the job outlook expects a fifteen percent growth in need from 2016-2026 (BLS, 2018). Further, it is projected that there will be more than 1 million registered nurse openings by 2024 and this is twice the number experienced in previous nursing shortages (Hospitals Set Up, 2018). Not only is there expected to be a nursing shortage in the next decade, there are issues with retaining nurses currently working in the field. Nurses across the United States describe that they experience unfriendly work environments that include bullying behaviors such as being ignored, belittled, confrontational, sexually harassed and a general lack of feeling supported, all of which influence nurses to leave the profession (Macusick and Minich, 2010). Bullying behaviors are certainly not new to the profession, and with projected increases in need and current issues with retention, attempts have been made to mitigate bullying behaviors with varying degrees of success. How is bullying currently perceived by nurses in a hospital setting? The purpose of this study was to understand the lived experiences of bullying among nurses in their professional environments. A phenomenological research design was used to support in-depth study of the nurses' experiences, their reactions to their experiences and how these experiences influence the nurses current and future career choices. Interviews with a variety of types of nurses were conducted and based on the participant's responses, the following four themes were identified, the definition of bullying is nuanced, bullying is facilitated through peer oppression, bullying silences the victim and the mission of the nurse can be at odds with the mission of the hospital. Based on the themes, the researchers propose four recommendations, to create a clear industry specific definition of bullying, ending the culture of silence, building a democratic power structures and recognizing the financial value of retaining nursing professionals.
\end{abstract}

Keywords: Nursing; Bullying; Retention; Healthcare; Management

\section{Introduction}

Albert Bandura, expert social learning theorist, identified that an individual's behavior is determined by a mixture of factors including cognitive, environmental and behavioral [1-4]. According to Olweus, bullying is a specific form of behavior that involves repeated, intentional aggression and includes a disparity of power between the victims and the perpetrators [5]. Bullying behavior can be overt or covert, involve harassment or mistreatment and even include social actions like, gossiping, exclusion or spreading rumors [6-8]. Bullying in the healthcare profession is occurring at a substantial rate [9]. Research indicates that workplace bullying among nurses is increasing globally and occurs more frequently among nurses than other professions. Bullying experiences begin for many pre-licensing nursing students in their clinical rotations [6,10]. More than $88 \%$ of nursing students reported experiencing bullying behaviors in the clinical environment and 73\% of newly licensed nurses reported being bullied [11,12]. A 2015 Occupational Safety and Health Administration (OSHA) study found that workplace violence in health care was prevalent, within a 12 month period of time, $21 \%$ of registered nurses and nursing students reporting that they were physically assaulted and over 50 percent reported they were verbally abused [13]. Bullying is a concern because there are numerous negative outcomes related to bullying for the nursing and medical profession. Researchers have found nurses exposed to direct or indirect hostility from their colleagues are more likely to leave their current employers or even the nursing profession all together [14-17]. In addition, nurses experiencing bullying can be plagued with numerous physical and psychosocial issues like stress, anxiety, sleep disturbance, impaired social skills, depression, fatigue, loss of concentration, helplessness and posttraumatic stress disorder $[18,19]$. Perhaps most significant, the care provided to patients by the affected nurse is often diminished [20,21]. In a 2008 Sentinel Event Alert, The Joint Commission noted that "intimidating and disruptive behaviors can foster medical errors and lead to preventable adverse outcomes" The following study will examine the lived experiences of professional nurses. Through the semi- 
structured interview process of the phenomenological method, the researchers will seek to gain further knowledge about the lived experiences, prevalence, implications, and possible solutions to bullying in current hospital settings. Specifically, we are seeking an in-depth understanding of the mixture of factors including cognitive, environmental and behavioral that support or extinguishing bullying behaviors in the nursing profession.

\section{Review of Literature}

In preparation for the interviews, the researchers conducted a limited review of literature seeking understanding of the concept and consequences of bullying. A more extensive review of the literature was conducted after data were collected as per phenomenology protocol. The literature outlined several key findings regarding the contemporary nursing work environment.

\section{There is a Shortage of Qualified Nurses}

In December 2014 the Health Resources and Services Administration (HRSA) released a report titled, "The Future of the Nursing Workforce: National- and State-Level Projections, 2012-2015 [22]." The reports highlights that the supply and demand of nursing professionals will continue to be affected by numerous factors and absolute projections are not certain, but the American Association of Critical-Care Nurses (AACN) predicts a nursing short fall of 500,000 RNs by 2025 (AACN, 2014) [23]. The potential shortage is due to many factors. First, the median age of the registered nurse (RN) is 46 (Townsend, 2016) and [24]. The Health Resource \& Services Administration anticipates more than 1 million RNs will reach retirement age within the next 10-15 years [25]. In addition to retirement, many nurses are choosing to leave the field. Nursing is an incredible stressful profession and burnout, fatigue and stress cause many nurses to leave prematurely [26]. MacKusick and Minick, conducted a study titled, "Why are Nurses Leaving? Findings from an Initial Qualitative Study on Nursing Attrition." The researchers interviewed 187 nurses and found, "Nurses talked about going home and crying, not only about the loss of their patients but also the loss of autonomy and respect as health care professionals in the institutes in which they worked," [3]. The nurses shared that their work environment, lacking in decision rights and respect, was contributing to their workplace distress.

Workplace distress can often be intensified when nurses are exposed to incivilities between co-workers and incivility, bullying and/ or lateral violence is known to be present in the nursing profession [27]. "Forty-five percent of nurses have been verbally harassed or bullied by other nurses, while $41 \%$ have been verbally harassed or bullied by managers or administrators," according to a survey by RN network [28]. Ovayolu, Ovayolu and Karadag conducted a study titled, "Workplace Bullying in Nursing," in which 260 nurses in three public hospitals was interviewed and data collected via questionnaires [29]. The researchers found that 58.5\% of the surveyed nurses did not want to go to work due to bullying, $66.2 \%$ had health or sleep disorders due to bullying and $13.1 \%$ faced verbal, physical or sexual harassment in their workplace. Of the participants reporting bullying issues, most had to seek psychological support to solve these problems. For decades researchers have identifying bullying as common within the nursing field [30-34]. And after years of study, the long-term negative effects of bullying in the nursing field are becoming clear, bullying in workplaces result in reduced job satisfaction, poor retention, adverse patient outcomes and mental and physical health effects to the nurses [35-37].

\section{Definition of Bullying}

Bullying is not always obvious, it comes in many forms. For this reason, there are many definitions of bullying. One definition characterizes bullying as "internally motivated and driven by a sense of fear, threat and lack of confidence; it is used primarily by women as a behavioral dynamic, where they feel better by hurting others," [38]. Another definition of bullying by the Violence Prevention Works Organization is, "A person is bullied when he or she is exposed, repeatedly and over time, to negative actions on the part of one or more other persons, and he or she has difficulty defending himself or herself," [39]. While numerous comprehensive definitions exist some commonalities, from definition to definition, can be identified and include concepts of, fear, lack of control and repeated exposure to hurtful behaviors. These aggressions are increasingly recognized as serious and even labelled as workplace violence [40]. But, the nebulous definitions of bullying that can encompass so many behaviors may contribute to confusion and the perception that the problem is impossible to solve [41]. Further, without a clear definition, many nurses are unaware they are being bullied [42]. Even when trying to report bullying, statements like, "I'm not sure if this qualified as bullying bu" is often shared [43]. A clear, nursing specific definition of bullying may be a foundational step in improving working conditions, "Given the work environment and the challenges faced by the nursing profession, a system-wide approach to intervention and management is recommended, along with utilizing a nursing-specific definition," [44].

\section{The Nursing Work Environment Breeds Bullying}

National surveys indicate that anywhere from $27 \%$ to $85 \%$ of staff nurses self-report exposure to bullying at work (Stagg, Sheridan, Jones and Speroni, 2013) [45]. In Bloom's literature review (2014), she found between $65 \%$ and $80 \%$ of nurses reported experiencing lateral violence when surveyed [46]. It is likely that most nurses, at some time in their career, will be a victim or bystander to bullying [47,48]. In fact, employees that work in healthcare have an increased risk of being bullied almost seven times higher than other professional populations [49]. "New nurses may be at an even higher risk of experiencing bullying with one study finding that as many as $90 \%$ had experienced some form of coworker incivility," [33]. Some may even consider bullying part of the job, leaving nurses to tolerate or expect the incivility [50]. There is an unfortunate saying that "nurses eat their young," [51]. 
While new nurses are at a higher risk, nurses at all levels of the organization experience bullying. "The older nurse may find themselves to be a target of bullying as younger nurses treat them as if their knowledge is out of date," [22]. Nurses with many years of experience may bully the younger nurses as a way of requiring them to "pay their dues" [52]. In the study, "Negative interactions among nurses. An explorative study on lateral violence and bullying in nursing work settings," (2018) the researchers conducted a web-survey of 5009 nurses in 3 public healthcare institutions, interestingly, lateral violence and bullying among nurses was consistently present in all studied settings [53]. Once a part of an organization, hostilities perpetuate more hostilities as bullying is contagious or cyclical, nurses who experience it are more likely to exhibit it later in their careers [54]. The growing cycle is then facilitated by "Inadequate support among nursing colleagues and silence and inaction by nurse administrators," [55]. Nurses operate in a culture of silence [56]. Silence and inaction by colleagues and managers allow the bullying cycle to continue [57].

These are many theories that explore why the nursing field in particular breeds bullying. One theory is that the nurse is an oppressed group due to their predominantly female gender and hierarchical physician dominance [58,51]. Purpora, Blegan and Stotts conducted the study, "Horizontal Violence among Hospital Staff Nurses Related to Oppressed Self or Oppressed Group." The study surveyed 175 hospital staff RNs from the California Board of Registered Nursing mailing list and based on survey results the researchers concluded " as nurses' internalized beliefs about themselves or women as a group consistent with being oppressed increased, so did horizontal violence" [59].

Researchers Ogle and Glass conducted an ethnographic study to investigate nurses' experiences with nursing management [60]. The researchers found that nurses' attrition is low in part due to unvoiced discourses and the presence of a double oppression, nurses are female in a male dominated world and a nurse is a subordinated health occupation [61]. The researchers describe with their study, "Nurses informed by dominant patriarchal and organizational discourses participated in constructing and reinscribing their own submissive identity reflected in interprofessional relations that lacked individual valuing and undermined their selfesteem," Oppression and exposure to aggression seem to be catalysts for bullying in the workplace [62].

\section{Bullying Contributes to Adverse out comes for the Hospital}

Bullying takes a toll on the medical professionals, but bullying is also detrimental to the medical facilities operations and finances. Bullying results in increased turnover among the nursing staff. Employee turnover has several negative organizational implications. Once a nurse leaves the organization, there are new challenges and costs associated with filling the open position. The cost to replace an $\mathrm{RN}$ ranges from $\$ 37,700$ to $\$ 58,400$ per nurse in a single replacement [63]. Annually, RN turnover for a hospital of 600 beds costs approximately $\$ 5.9$ million to $\$ 6.4$ million [64]. Bulling behaviors exact costs beyond turnover to the organization. The estimated legal cost for per lawsuit is $\$ 30,000$ and if the claim goes to court, $\$ 60,000$ [65]. But, another expense to consider is the loss of productivity. A bullied employee can experience low productivity, absenteeism and even post-traumatic stress disorder. Hutton and Gates conducted a study of $145 \mathrm{RNs}$ and found that unproductive behaviors result in a financial loss of more the $\$ 1,400$ per employe [66].

High turnover is compounding other existing issues. Nurses already struggle with efficiencies and feel they are overworked. A survey of 10,000 staff by the Royal College of Nursing revealed that $62 \%$ of nurses thought about quitting due to being overstressed, $61 \%$ felt unable to give patients the care they wanted because they were too busy and $83 \%$ reported feeling their workload had increased over the last 12 months [67]. More than 400,000 patients die from preventable medical errors and preventable medical errors cost our country tens of billions of dollars a year [68,69]. Kumar and McKewan surveyed 53 nurses from hospitals and small medical clinics about the expanded nurse practitioner's role, the survey results found that nurses feel there should be more nurses in the hospitals and if the number increased, patient care would increase. Nurses are already over worked, turnover should be avoided when possible [70]. Finally, healthcare managers are being pushed towards profits and "good business." During the last 20 years, the number of for-profit health care facilities, ranging from national hospital chains has grown at a rate that exceeds even the computer industry [71]. Healthcare administration have a focus on profit which may cause hospital leadership to watch quantitative hospital experiences more than qualitative, ultimately pursuing the notation that health and health care are commodities to be bought and sold in the market [72]. For profit medical facilities are shifting patients to other facilities not for medical reasons but for economic reasons and pursuing advantaged technologies, organizational prestige [71]. Addressing bullying could be a cost savings action for administration, a comprehensive costs of workplace bullying are estimated to be over $\$ 250$ million annually in expenditures related to health care, litigation, employee turnover and retraining [73].

\section{Methodology}

This research study applied a descriptive, qualitative method, specifically, phenomenology. Qualitative research has the purpose of describing and interpreting how people assign meanings to phenomena that occur naturally in their interpersonal contexts [74]. Phenomenological research focuses on the individual's interpretations and perceptions of these experiences [75]. As the research was intent on understanding nurse's lived experiences and their interpretations and perceptions of their lived experiences, a phenomenological research design was used. Phenomenological research allows for a comprehensive consideration of the participants, considering the whole person, their values and their experiences. This comprehensive consideration is needed to understand the full experience and long-term implications of bullying in the nursing profession. Ultimately, the methodology allows the researcher to acquire and later convey lived experiences of the research participants. Life experiences are difficult to 
study through quantitative inquiry, as individual experiences cannot be replicated [76].

\section{Participants}

\section{Semi structured interviews with Nursing Professionals}

The participants in the study included 12 adults - 11 women and 1 man. Phenomenological research practices regarding the appropriate number of participants varies however, a recommended sample size includes three to ten participants [77,78]. All were nurses with various titles and experiences and all participants were between the ages of 18 and 73 years old.

The specific population of human subjects involved nurses in hospital settings at institutions throughout the United States. Participants were recruited via professional list serves, professional websites, word of mouth, the snowball effect, and direct communication. There are no exclusion criteria. IRB approval was granted by West Texas A\&M University. All individuals were assured that their participation was voluntary, information will be kept confidential, and data would be reported in aggregate or using a pseudonym and they had the option to withdraw from the study at any time. Table 1 provides participant demographics (See Appendix).

\begin{tabular}{|c|c|c|c|c|}
\hline Code & Age & Gender & Nursing License & Years in Profession \\
\hline $\mathbf{1}$ & $20-29$ & F & BSN & 6 \\
\hline $\mathbf{2}$ & $40-49$ & F & LVN & 16 \\
\hline $\mathbf{3}$ & $60-69$ & F & RN & 30 \\
\hline $\mathbf{4}$ & $20-29$ & F & LVN & 9 \\
\hline $\mathbf{5}$ & $20-29$ & F & CAN, CMA & 3 \\
\hline $\mathbf{6}$ & $70-79$ & F & BSN & 31 \\
\hline 7 & $40-49$ & F & BSN, MSN, DNP & 21 \\
\hline $\mathbf{8}$ & $20-29$ & F & RN & 5 \\
\hline $\mathbf{9}$ & $40-49$ & M & RN & 22 \\
\hline $\mathbf{1 0}$ & $50-59$ & F & RN, MSN & 38 \\
\hline $\mathbf{1 1}$ & $40-49$ & F & RN, BSN & 19 \\
\hline $\mathbf{1 2}$ & $20-29$ & F & RN & 5 \\
\hline
\end{tabular}

\section{Research Questions}

Research Question 1: Do nursing professionals experience bullying in the workplace?

Research Question 2: How does bullying behavior impact the nurse's responsibilities?

\section{Procedure}

This phenomenological research completed the following steps: initial review of literature, identification of the phenomenon, selection of informants, obtaining first person descriptions (interviews), transcribing the descriptions, reading the descriptions, breaking the descriptions into themes and analyzing the themes, additional review of literature. Both researchers conducted interviews and equally participated in and contributed to all the research steps. Participation was voluntary, and the participants had the right to withdraw from the study at any time without penalty. Participants were solicited via purposive sampling of Registered Nurses (RN) and Licensed Vocational Nurses (LVN) working in a hospital setting. Participants must have the ability to speak and understand English. Additional participants were solicited using a snowballing strategy. The goal of the research was to gain understanding about the nursing work environment and lived experiences [79]. Participants were told that the study would involve an interview lasting approximately one hour, but additional time may be required to clarify or confirm responses. Data was obtained in an interview at a location convenient to the participant but conducive to the interview process and to maintaining confidentiality. Each interview was audio taped with the permission of the participant. Minimal demographic data was obtained, to include: age, gender, race/ethnicity, licensure (RN or LVN), years in practice, and practice location. In their interview, participants were asked to respond to four basic prompts:

1. How would you define bullying?

2. Tell me a story of a time you felt bullied at work.

3. Describe how this affects your personal and professional life.

4. How would you envision your workplace without bullying?

Interview prompts, how would you define bullying? And tell me a story of a time you felt bullied at work, provided insight into Research Question 1: Do nursing professional experience bullying in the workplace? and Interview prompts, Describe how this 
affects your personal and professional life and How would you envision your workplace without bullying?, provided insight into Research Question 2.Direct participant observation, participant interviews, and reflective field notes were analyzed for dominant and subjugated discourses.

To identify the relevant themes, the researchers transcribed the recorded interviews, key words were identified, and common experiences were categorized. Based on the most frequent words and experiences, themes in the nurse's experiences were identified. Table 2 provides key statements that became the foundation for study themes (See Appendix).

\begin{tabular}{|c|c|}
\hline \multirow{12}{*}{$\begin{array}{l}\text { The definition of } \\
\text { bullying is nuanced. }\end{array}$} & P1- trying to hurt someone \\
\hline & P2- anything someone does to make another feel inferior \\
\hline & P3- professional relationships that aren't going well \\
\hline & P4- trying to intimidate someone else by several measures \\
\hline & P5- causing another person's self-esteem to go down \\
\hline & P6- someone that thinks they are superior to you \\
\hline & P7- verbally or even just like non-physical looks that do not approve of your actions \\
\hline & P8- making someone do something they are uncomfortable with \\
\hline & P9- incivility towards another individual that can be verbal than can be physical, emotional and spiritual \\
\hline & P10- either with non-verbal cues and maybe making someone feel inadequate and also possibly being killed using a gun. \\
\hline & P11- behaviors or actions from one person in order to belittle or be mean to another person \\
\hline & P12- someone being mean to another person for no reason \\
\hline \multirow{12}{*}{$\begin{array}{l}\text { Peer oppression is } \\
\text { present in the hospital } \\
\text { setting. }\end{array}$} & P1- nurses eat their young \\
\hline & P2- just yesterday a senior nurse said she was the "real" nurse \\
\hline & P3- there is no place where you can appeal anything \\
\hline & P4- doctors intimidated the nurses \\
\hline & P5- for some people, it makes them stronger \\
\hline & P6- senior nurses would pick on me for little things \\
\hline & P7- senior nurses will knock you down for what you're trying to do or how your trying to help the patient \\
\hline & P8- case manager and the charge nurse and they screamed at me \\
\hline & P9- unfairly written up \\
\hline & P10- ordered by a senior nurse to follow procedures that the nurse did not agree with or understand \\
\hline & P11- We always want to say yes, yes, yes, yes even though sometimes we need to say no I can't take that on. \\
\hline & P12- I knew they were talking about me and I felt I shouldn't be here \\
\hline \multirow{12}{*}{$\begin{array}{l}\text { The victims of bullying } \\
\text { are silenced. }\end{array}$} & P1- we do not have time to teach the younger nurses, they need to move out of the way \\
\hline & P2- how I don't want to be here, and I don't want to talk to you \\
\hline & P3- I was told to turn my back and ignore it or quit \\
\hline & P4- everything worked better on the days she was gone \\
\hline & P5- some people just go one and shame themselves \\
\hline & P6- I feel I feel more scared to say things out loud \\
\hline & P7- I dropped the papers in my hand, walked out the building and called later to give my resignation \\
\hline & P8- the case manager never spoke to me again \\
\hline & P9- I didn’t feel like I had anyone to talk to \\
\hline & $\begin{array}{l}\text { P10- I am pretty much over that except I can still see her face and she almost did not talk to me for the rest of my time there } \\
\text { and I worked there } 18 \text { years }\end{array}$ \\
\hline & P11- you may have one person that you talk to \\
\hline & P12- And just this look of why are you talking to me \\
\hline \multirow{6}{*}{$\begin{array}{l}\text { The mission of the } \\
\text { nurse is at odds with the } \\
\text { mission of the hospital. }\end{array}$} & P1- we don't have time to teach \\
\hline & $\begin{array}{l}\text { P2- setting up nurses for failure or sending them into a situation they know they don't have the experience to be } \\
\text { successful }\end{array}$ \\
\hline & $\begin{array}{c}P_{3} \text { - and you really couldn't communicate that was problem the way the structure and you know we always just get in an } \\
\text { do }\end{array}$ \\
\hline & $\mathrm{P}_{4}$ - on the days she was not there, the flow was much better \\
\hline & P6- it would be better patient care overall without bullying \\
\hline & P7- I was given the opportunity to develop my position and she became jealous of me \\
\hline
\end{tabular}


P8- I am worried and in the meantime the patient is not getting the help he needs

P9- So I just kept my mouth shut and did my job as best I could do it the best patient care I possibly could and then I resigned.

Table 2: Summary of Participant Statements Interview Themes

\section{Results}

\section{Themes}

From an analysis of the participant comments, four themes were identified. First, the definition of bullying is nuanced. Second, peer oppression is present in the hospital setting. Third, the victims of bullying are silenced. Fourth, the mission of the nurse is at odds with the mission of the hospital.

\section{The definition of bullying is nuanced}

Bullying can be difficult to define, in part because the definition of bullying is nuanced. Interview question one, How would you define bullying?. Asks participants to defined bullying in their own words. Participant 08 communicates the nebulous boundaries around the definition of bullying by saying, "That's it. Bullying in my eyes." The individual is explaining that their definition of bullying is based on how they see the world and how they understand their unique experiences. Everyone will have a somewhat nuanced perspective on appropriate behaviors and their meanings in the workplace.

What constitutes bullying for one individual may not be considered bullying at all, to another individual. Each person is a product of their culture, family, experiences, perceptions, etc. They will each see tones, verbiage, behaviors and actions on a spectrum that defines acceptable and unacceptable behaviors. When a variety of individuals come together to work within one setting, it is difficult to communicate and define the behaviors that will be tolerated within the professional organization. When there are so many definitions of behaviors that can fall within a range of bullying, it becomes more difficult to manage. The participants in this study define workplace bullying as everything from unkind looks to physical violence. In their definitions, research participants described both covert, passive aggressive and overt, openly aggressive behaviors. Common descriptors of covert bullying included the spreading of rumors, making people uncomfortable, disapproval of actions or beliefs, gossip, unkind looks, judgments, making others feel inferior, causing someone's self-esteem to go down or punishing people unnecessarily. Participant 09 explains, "you hear through the grapevine that they called you the name," while Participant 06 discusses an experience with a senior nurse sharing, "she would pick on me with the little things you know ...saying no we don't do that till later."

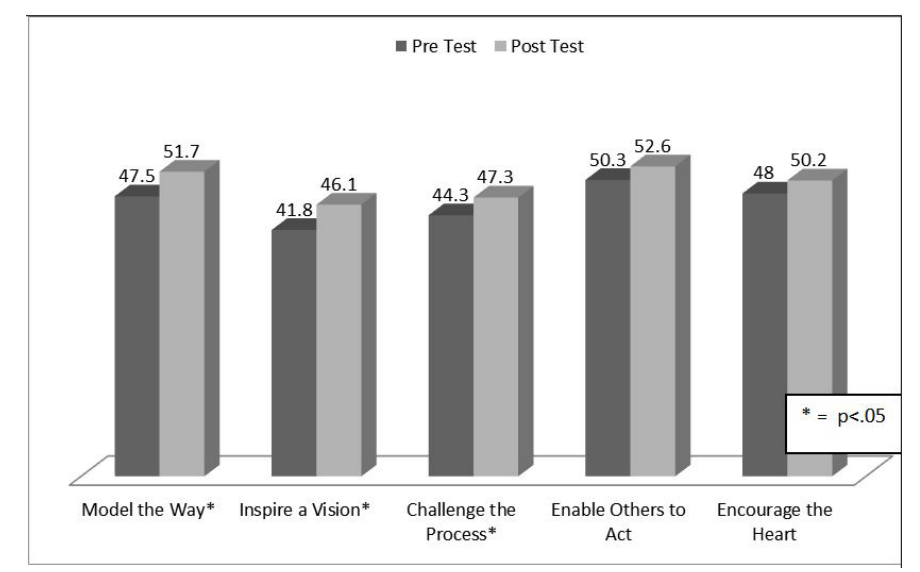

Figure 1: Study Theme One: The Definition of Bullying is Nuanced, A Spectrum of Bullying Behaviors 
While overt bullying behaviors were identified with verbal and physical altercations. Participant 05 and 08 , respectively, described their verbal altercations, "I was with people that would talk smack about other people," and "But then when you get yelled out or reprimanded or an eye roll or horrible assignment you think they're punishing me because I'm not doing something right." Two participants describe experiencing physical violence in their work setting. Participant 03 describes, "I went to work one morning and my patients were beaten down by the staff on night," and Participant 09 found threatening notes in their work locker, "If it is notes on the locker, I would only assume it was the people I worked with but I couldn't prove anything."

As the participants defined bullying in their own words, they reflect on personal events, where they were victimized or bullying events that they observed. For this group of participants, bullying involved actions by the perpetrator that damages the victim; this can include damage to their physical self or to their self-esteem. Further, bullying, for these participants, is something that is easily recognized by the victim, but not definitively observable by all other bystanders. Bullying is nuanced. Figure 1 shows the spectrum of behaviors identified by the participants that constitute bullying in the workplace (See Appendix).

\section{Peer oppression is present in the hospital setting}

The second interview question posed was, “Tell me a story of a time you felt bullied at work." All twelve participants described observing bullying at work within their medical facilities. Ten participants chronicled being the victim of bullying during working hours and two described only observing bullying in their workplace. As these ten individuals explained their victimizing experiences, they were all able to recall the events, the timeline, the perpetrator and how the experience impacted them emotionally. Interviewees describe experiences with bullying that involved co-workers, supervisors, patients, subordinates and physicians.

When experiencing hostility from co-workers, the nurses described angry tones and disdainful looks. Participant 06 shared that bullying began for her when she changed from the Day shift to the night shift. Beginning her first night shift, the participant described that the Older nurse would pick on her, saying she did her job "wrong," and would order her to move from rapidly from responsibly to responsibility. It was not necessarily the words the senior nurse used, rather the tone that the participant recognized as bullying, Participant 06 described the tone, and "she's very hateful with it."

Supervisory conflicts were also discussed, with Participant 02 explaining that she earned her Licensed Vocational Nurse degree at a community college and she felt bullied by other nurses that have higher credentials and higher degrees. Participant 02 , believes that the hierarchy of credentials creates hostility between the nurses and causes ongoing belittling from nurses with higher designation. She recalls RN's telling her, "I am the real nurse here." As Participant 02 recounted this story she said, she wished she had told the $\mathrm{RN}$, "I am a real. I am a real nurse. I can have the same job that she has."

Many nurses describe bullying not only from co-workers, but also from demanding patients. It was explained that the patients were often rude because they are scared, uncomfortable or not familiar with the role of the nurse. This creates an environment where many patients move beyond self advocation to attacking the nurses. Participant 01explained, "Patients can just be demanding, and they may not understand that I can't do everything right now or I can't fulfill all their wishes. You're going to run into more demanding patients than you are into demanding nurses."

Some interviewees communicated challenges that stemmed from hostile nursing subordinates and trainees. The interviewees noticed covert attacks on them as the trainees progressed in their own careers. Participant 02 describes of her trainee, "She was going through nursing school and I taught her how to pull staples, how to apply start catheters, how to start IV's. I taught her all of these things and she graduated from nursing school and all of a sudden, the table was turned. She turned on me and it ended up with her thinking she has a BS now she'll tell me what it is all about." The participant explained that once the trainee had her bachelor's degree, she changed and believed she knew more than the nurse that mentored her through school.

Nurses also shared their perspectives about physicians that bully. Participant 04

Explained that she had not experienced bullying from other nurses rather, she had experienced being talked down too by physicians, "I have witnessed bullying from others like towards other people. So beside that my only experiences were basically being kind of demeaning and talked down to by physicians not really other ancillary services or other nurses."

Explained that she had not experienced bullying from other nurses rather, she had experienced being talked down too by physicians, "I have witnessed bullying from others like towards other people. So beside that my only experiences were basically being kind of demeaning and talked down to by physicians not really other ancillary services or other nurses."

Two nurses felt they experienced such extreme bullying that they had to leave their place of employment. Both perceived that the hostility at their hospital was physically dangerous. Participant 03 described a very concerning experience involved patient abuse and a supervisor that was willing to intimidate the nurse into leaving rather than protecting the patients. "I worked in the city hospital and I went to work one morning, and my patients were beaten down by the staff at night. Well the staff on the night shift was in the union. I called my supervisor after I took care of my crying patients and asked what I could do. She said turn your back and ignore it or quit. I decided to resign." The second nurse, Participant 09, experienced extreme bullying and chose to leave not only their hospital but the town in which they were living, "It was when people in this small rural town found out that I was gay and that was not socially accepted so that quickly spread throughout the hospital and affected my work performance. And I've only 
been written up that one time in my life for anything and it was at that hospital and I just didn't believe it was related to my skills. I believe it was retaliation for finding out that I was gay. And so, I quickly resigned and moved to a larger hospital in a larger town." Participant 09 elaborated further on their experience saying, "I had my car keyed in that town in the parking lot of that hospital. Fellow employees in that hospital called me names, said faggot, queer. I was told I was not welcome there and I had no slot for my locker." With these extreme circumstances, these two nurses felt the only safe option they had was to resign.

There were two participants, who, while they had observed bullying against others, they themselves did not perceive that they had experienced bullying at work. While neither felt they had been victims of an uncivil work environment, these two individuals had distinctly different perspectives about workplace hostilities. Participant 04 felt she was at work each day to care for and save the lives of others and, she was okay with any feedback that was directed. She explained, the tone surrounding the feedback was not of concern rather that the patient care is of the highest quality, of bullying she said, "I mean it didn't happen. It wasn't present in my day 1970s during the Hospital or in college. I just didn't happen. We were working together for a common goal to the patient care. I don't remember ever being bullied by the nurses and the doctors in the 28 years that I worked." The second individual, Participant 05, stated that they had observed bullying at work but had not been bullied themselves. This participant felt that bullies might not be aware they were hurting others and under some circumstance, bullying could make the victim stronger. Of bullying she said, "I think it is just like air. It's just kind of hard to avoid like you're always getting something nasty." This participant did not emotionally engage with bullying experiences.

In reflection upon all of the stories, common descriptors can be identified. The participants used words like, "fear," "tears," "looking over their shoulder," and feelings of insecurity to describe their responses and these emotions were created through experiences associated with peers, "yelling," being "hateful," seeking "retaliation," and "talking about each other" behind backs or closed doors were used to explain the perpetrators. For these participants, bullying was facilitated, in part, because hierarchies permitted the behaviors. In other words, the nurses were considered by the patients and by the doctors as the lowest level authority and even within the nurses, ranks of hierarchy were established.

The organizational power structure, when rigid and controlling supports oppression [80]. The nurses describe working within several hierarchies. One hierarchy is among the nurses themselves where rank is associated with the nurse's level of education and credentials. The more educated and the more credentialed, the higher the rank. Nurses also reported levels of seniority based on years of experience. Again, the more senior, the higher the rank. Finally, nurses describe operating in a hierarchy among the medical staff in which doctors, physicians and surgeons out rank the nurses. These hieratical structures result in layers of employees of categories and ultimately contribute to oppression. The nurses are oppressed by the physicians and surgeons and ultimately the nurses turn inward and oppress each other. Hierarchies offer ranks and control ultimately fostering and facilitate bullying, lateral violence and hostility [80].

The nurses shared many comments that show they felt oppressed in the hospital. For example, Participant 02 said, "I am the real nurse," and "When I worked in nursing it was really female dominated. So that made it harder because women aren't necessarily nice to each other." Participant 08 described themselves as, "I’m just a little bitty nobody" and Participant 07 explained in detail oppressive experiences from a senior nurse because the senior nurse was jealous of the junior nurse's work accomplishments, "So she's like twenty-five years older than I am and instead of encouraging me or acknowledging my accomplishments, she would try to take the accolades for things I had done or put me down and say stuff like you know because I'm not married, and I don't have children."

An unexpected perspective on oppression appeared as a few of the participants explained that they had to ignore or "shut down," some of the junior level nurses because they were not prepared to do their jobs, Participant 01 said, "And it's not necessarily that you don't want them there or you don't want to see them succeed but you have so much to do and it's hard to teach them as well. Take care of everything. Of teaching. And that's where situations can get really tense because you're running around crazy and they're just standing there or asking a million questions and it's like either we get this done or we never get out of here. So, it can it can become tense. And I am sure you've heard the saying that nurses eat their young." This nurse felt she had to oppress the junior nurses' actions because they were not prepared to accomplish their tasks.

Additionally, several nurses made comments during their interviews that excused bullying behavior. Participants 05 excused the bully's behavior with statements like, "I don't think they realize they are bullying," and "I think for some people, being bullied, makes them stronger." While Participant 10 said "I deserved it," and "They are just ranting and you have to let them rant." These statements consider the needs of the bully as the most significant in the working relationship and indicate that those around the bully should extend greater patient, greater understanding or improved behavior so that the bully does not have to react. Participant 12 describes her bullying experience as, "going through the initiation or hazing phase with them so that they accept me and I will be one of them." This statement indicates that being bullied is an acceptable aspect of becoming a nurse and without the experience, one might not truly be recognized as a member by their nursing peers. Oppression thrived in the nurse's environments for two reasons. One, when some nurses faced bullying, the become paralyzed with indecisiveness and accepted a role of oppression. Two, some nurses support oppression as part of the nursing culture, either for maintaining control over less qualified nurses or as part of a professional "rite of passage." 


\section{Victims of bullying are silenced}

The third interview prompt presented to all participants was, "Describe how this affects your personal and professional life." All participants viewed that bullying had impacted their personal and professional work environments. All had observed bullying and ten had experienced bullying behavior directed towards themselves within a hospital setting. From these observations and experiences, the participants were changed. The participants describe that from observing and experiencing bullying they learned in some environments they should not to say anything, choose not to report, choose not to ask questions, choose to avoid certain people and finally to conform with the bully in hopes of avoiding any or further attacks in the future. The participants describe making the choice of silence or avoidance because they feared the bullying would get worse or become fixated on them. 11 of the 12 participants could definitively state that bullying in the hospitals negatively impacted the medical procedures and operations, such as "slowing communication," "reducing questions" and "causing increased anxiety."

11 of the 12 participants felt that bullying resulted in silencing. Not only, silencing the victims but also silencing the observers. Participant 06 recounted her experience of bullying with statements like, "I feel I feel more scared to say things out loud for the fear that someone else would not agree with me or take me for that reasoning." Participant 01 said, "I have to protect myself from it." Participant 07 further explained "I think nurses are right to believe that it's not OK to ask questions which you know don't help improve patient care and bullying also comes in the form of feeling like you can't ask questions and if you do you'll be put down for that." While these examples are interpretation and feelings, some nurses were directly told to remain silent. Participants 03 shared a comment made by her manager, "She said turn your back and ignore it or quit."

There were some interviewees that felt they might want to report negative workplace behaviors but expressed that even if they wanted to speak up about bullying concerns, there was no place to report. Participant 09 stated, "I didn't feel like I had anyone to talk to so I kept my mouth shut," Participant 12 shared, "I felt the need to say something but didn't," and Participant 03 explained, "There is no place where you can appeal anything because the whole thing was corrupt."

When bullying occurs, the victim will consider and examine if there is any potential for help or support. If the victim determines that no one will help, or that seeking help will be more difficult that withstanding the bullying, the victim will be silenced. Once silenced, the individual will cease to ask questions. The individual will cease to speak up about injustices. The individual will conform, to the bullying expectations or leave the hospital. When segments of an employee teams are silenced or leaving, quality of care can be minimized.

The interviewees also stated that along with silence, the bulling impacted their ability to care for patients. Participant 01 explains, "Makes it very difficult to take care of those patients especially those patients. And then it becomes like you just don't do it. You get enough of that anyway and then you're not as nice to any patient." Participant 10 expounds that bullying supports a toxic environment which makes the job more challenging and the patients ultimately suffer, "You know that the job itself is already hard enough. You already have very ill patients. Every year it seems like you had more and more tasks to do if you were a few people to help you to do that. So, it was already a very demanding job anyway. It is extra hard when you felt like you were going into an environment with you know where everything just felt negative."

For the victims of bullying attacks, they describe that they were not only affected at work, they describe the workplace stress as carrying over to and affecting their personal lives. Even at home, these individuals experienced heightened anxiety, heightened stress, worry for future attacks. Participant 09 contemplated suicide, "There was a time I would never want to go back. I honestly thought I would commit suicide." Four individuals describe drastic life changes they pursued to get away from the bully. Two participants chose to sell their homes and move to other cities and two other participants chose to leave their jobs and return to graduate school.

When people feel they have no support and no voice, many will choose to remove themselves from environments that cause distress. If bullying continues unchecked, the nurses that can leave their jobs, will leave. Figure 2 illustrates that oppression supports bullying and bullying facilitates silence (See Appendix).

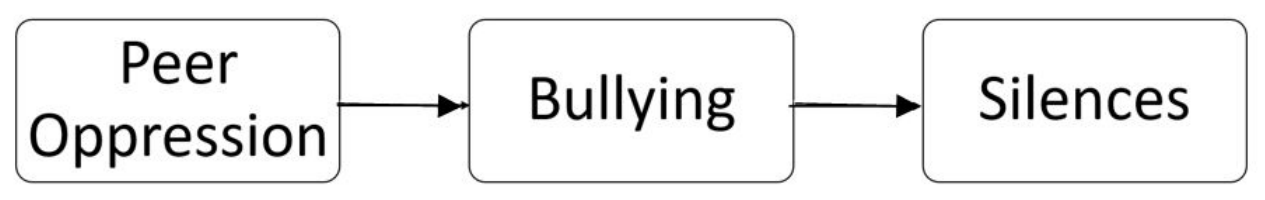

Figure 2: Study Theme: Oppression Supports Bullying and Bullying Facilitate Silence

\section{The mission of the nurse is at odds with the mission of the hospital}

The final interview prompt asked of all participants was, "How would you envision your workplace without bullying?" 10/12 participants were able to consider a workplace without bullying and they described this fictitious work environment as entire departments cohesively working together, with greater efficiency, improved communication, improved quality of care, more 
teamwork, safe, better patient care, people asking questions, people making suggestions, team meetings, no fear and ultimately, and ultimately a workplace where one could enjoy going to work.

Some participants explained that a workplace without bullying would create a happy work environment. Participant 05 expresses, "I feel that it would be a lot more teamwork," and Participant 07 shared, "I think also emotionally you would enjoy going to work more. I think just your quality of life would be better." Ten of the nurses were clear that a hospital without bullying would result in better patient care. Participant 06 specifically states, "Everyday people patients will get better care." Participant 11 clarifies, "And I feel like there would be better patient care overall" and Participant 07 stated, "You know I think honestly it would actually impact patient care more than we realize. I think once when you're supported by your co-workers and you are not fearful of asking questions or making suggestions that patients are the ones that benefit from that and we forget that you know when you sit in a team meeting and you're afraid to open your mouth because of your senior nurses or your or your colleagues that at the same level the patient outcomes suffer from that."

Finally, two interviewees believed the work environment would be better without bullying, however, they were not able to really envision a civil work environment. Participant 05responded saying, "that's kind of hard because again like bullying like you don't know you're doing it," and the Participant 09 explained, "There will always be a little bit of backbiting. I think that's just to say the task seems to be human nature I've certainly been guilty of that in the past myself."

Participants believed, overall, a workplace without bullying would result in improved nurse job satisfaction and in improved patient care. With the recognition that an end to workplace bullying among nurses could result in an improved work environment and better patient care, why is bullying allowed to continue? One theory is that the mission of the nurse, at times, is at odds with the mission of the hospital. Nurses spend much of their time in direct contact with patients. The nurse has many roles from administering medicine to helping patients transition from life to death and at times, it is difficult to quantify the nurse's role in terms of dollars and return on investment. With this said, the nurses additional time or unquantified contribution, can appear at odds with the mission of the hospital and this can cause conflict. Participants describe that conflicts and hostility develop over lack of resources, with Participant 03 explaining, "So there was this rub about money," and Participant 08 stating, "you hear over and over I don't have time," and "Sometimes there isn't time and it's not necessarily the nurse's fault all they sometimes get the impression that as nurses instead of managing patient care they are managing the clock."

When the focus of the hospital is on profits, a concern for nurse's wellbeing and ultimately

Patient well-being takes a back seat. Participant 01 shared, "It's because you know we don't have

Time to teach them because were already overwhelmed as it is." Participant 08 explains,

"I think nurses are busy with all of their tasks that we don't have time to talk to the patient or Include or teach the patient," and this results in a "Hardened heart towards this profession."

\section{Miscellaneous but important participant comments}

The researchers want to include a particularly meaningful statement made by one of the participants. The research asked "So, you said you know what kind of nurse you don't want to be. Tell me more about that nurse." And the Participant 08 responded, "One that has no patience- has no forgiveness." This comment speaks to basic human relations skills that are needed to be professional and needed to be healthy contributors to an organization. Forgiveness is a valuable employee characteristic that is needed for long term organizational effectiveness. Also, Participant 10 concluded, "You know your heart was unsafe because of the bullying behavior." This is a powerful statement that highlights the challenge of managing bullying. Bullying can be covert, so it is difficult to prove or contain. But proof is not necessary for the victim of bullying to know what they experienced and for many that experience, bullying, is painful, scary and life altering.

\section{Discussion on Interventions}

The purpose of this study was to understand the lived experiences of bullying among nurses in their professional environments. After the review of literature and the analysis of interview data, the researchers have identified four areas of potential interventions regarding bullying in the nursing field. Specifically, creating a clear definition, supporting a voice, active reduction of peer oppression, and aligning the organizational power structure with the mission of the nurse. Table 3 illustrates the alignment between the literature review and participant responses (See Appendix).

\section{The Definition of Bullying is Nuanced}

Bullying goes by many names, harassment, horizontal violence, lateral violence, vertical violence, hostility, abuse, intimidation, offensive, disruptive behavior and even mobbing. The varied terminology is in part due to the fact that bullying is an experience that is uniquely interpreted by each individual. However, May and Grubbs argue that lack of a clear definition led to underreporting incidents of workplace violence so masking its extent and creating confusion among nurses about whit is constitutes [81]. While a broad definition of bullying may be difficult to solidify, a simplified definition will allow for a minimization of the issues [82]. 


\begin{tabular}{|c|c|c|}
\hline Literature & Descriptor & Alignment with participant experiences. \\
\hline \multirow{12}{*}{$\begin{array}{l}\text { Bazelon, 2013; Thompson, 2017; Birks, } \\
\text { Budden, Biedermann, Park and Chapman, } \\
\text { 2017; D’Souza, Forsyth, Tappin and Catley, } \\
2018[42-44,89]\end{array}$} & \multirow{12}{*}{$\begin{array}{l}\text { The definition of bullying is } \\
\text { nuanced. }\end{array}$} & P1- trying to hurt someone \\
\hline & & P2- anything someone does to make another feel inferior \\
\hline & & P3- professional relationships that aren't going well \\
\hline & & P4- trying to intimidate someone else by several measures \\
\hline & & P5- causing another person's self-esteem to go down \\
\hline & & P6- someone that thinks they are superior to you \\
\hline & & $\begin{array}{l}\text { P7- verbally or even just like non-physical looks that do not approve of your } \\
\text { actions }\end{array}$ \\
\hline & & P8- making someone do something they are uncomfortable with \\
\hline & & $\begin{array}{l}\text { P9- incivility towards another individual that can be verbal than can be } \\
\text { physical, emotional and spiritual }\end{array}$ \\
\hline & & $\begin{array}{l}\text { P10- either with non-verbal cues and maybe making someone feel } \\
\text { inadequate and also possibly being killed using a gun. }\end{array}$ \\
\hline & & $\begin{array}{l}\text { P11- behaviors or actions from one person in order to belittle or be mean to } \\
\text { another person }\end{array}$ \\
\hline & & P12- someone being mean to another person for no reason \\
\hline \multirow{12}{*}{$\begin{array}{l}\text { Kathleen Croft and Anne Cash, 2012; } \\
\text { Purpora, Blegan and Stotts, 2012; Rodwell } \\
\text { and Demir, 2012; Manton, } 2017 \text { [51,58,59,62] }\end{array}$} & \multirow{12}{*}{$\begin{array}{l}\text { Peer oppression is present } \\
\text { in the hospital setting. }\end{array}$} & P1- nurses eat their young \\
\hline & & P2- just yesterday a senior nurse said she was the "real" nurse \\
\hline & & P3- there is no place where you can appeal anything \\
\hline & & P4- doctors intimidated the nurses \\
\hline & & P5- for some people, it makes them stronger \\
\hline & & P6- senior nurses would pick on me for little things \\
\hline & & $\begin{array}{l}\text { P7- senior nurses will knock you down for what you're trying to do or how } \\
\text { your trying to help the patient }\end{array}$ \\
\hline & & P8- case manager and the charge nurse and they screamed at me \\
\hline & & P9- unfairly written up \\
\hline & & $\begin{array}{l}\text { P10- ordered by a senior nurse to follow procedures that the nurse did not } \\
\text { agree with or understand }\end{array}$ \\
\hline & & $\begin{array}{l}\text { P11- We always want to say yes, yes, yes, yes even though sometimes we } \\
\text { need to say no I can't take that on. }\end{array}$ \\
\hline & & P12- I knew they were talking about me and I felt I shouldn't be here \\
\hline \multirow{12}{*}{$\begin{array}{c}\text { Gaffney, DeMarco, Hofmeyer, Vessey and } \\
\text { Budin, 2012; Thomspon, 2015; Wilson, } 2016 \\
{[56,57,90]}\end{array}$} & \multirow{12}{*}{$\begin{array}{l}\text { The victims of bullying are } \\
\text { silenced. }\end{array}$} & $\begin{array}{l}\text { P1- we do not have time to teach the younger nurses, they need to move out } \\
\text { of the way }\end{array}$ \\
\hline & & P2- how I don't want to be here and I don't want to talk to you \\
\hline & & P3- I was told to turn my back and ignore it or quit \\
\hline & & P4- everything worked better on the days she was gone \\
\hline & & P5- some people just go one and shame themselves \\
\hline & & P6- I feel I feel more scared to say things out loud \\
\hline & & $\begin{array}{l}\text { P7- I dropped the papers in my hand, walked out the building and called } \\
\text { later to give my resignation }\end{array}$ \\
\hline & & P8- the case manager never spoke to me again \\
\hline & & P9- I didn't feel like I had anyone to talk to \\
\hline & & $\begin{array}{l}\text { P10- I am pretty much over that except I can still see her face and she almost } \\
\text { did not talk to me for the rest of my time there and I worked there } 18 \text { years }\end{array}$ \\
\hline & & P11- you may have one person that you talk to \\
\hline & & P12- And just this look of why are you talking to me \\
\hline \multirow{4}{*}{$\begin{array}{l}\text { Brody, 2014; Andre and Velasquez, } 2015 \\
\text { [71,72] }\end{array}$} & \multirow{4}{*}{$\begin{array}{l}\text { The mission of the nurse is } \\
\text { at odds with the mission of } \\
\text { the hospital. }\end{array}$} & P1- we don't have time to teach \\
\hline & & $\begin{array}{l}\text { P2- setting up nurses for failure or sending them into a situation they know } \\
\text { they don't have the experience to be successful }\end{array}$ \\
\hline & & $\begin{array}{l}\text { P3- and you really couldn't communicate that was problem the way the } \\
\text { structure and you know we always just get in an do }\end{array}$ \\
\hline & & P4- on the days she was not there, the flow was much better \\
\hline
\end{tabular}




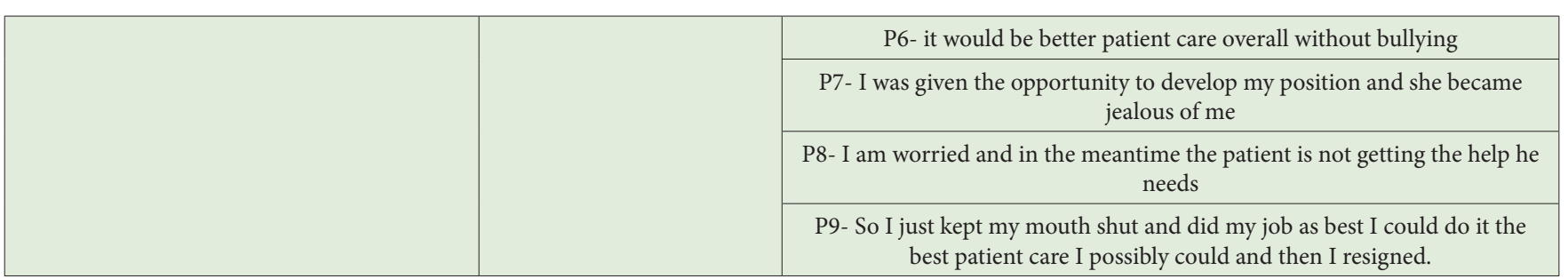

Table 3: Summary of participant experiences with bullying as aligned with the literature review

Researchers Leong and Crossman (2016) conducted a qualitative study examining the transition experiences of new nurses and supervisor strategies termed "tough love." The researchers found that senior nurses use the term "tough love" to prepare nurses for independence, but while possibly well-intentioned abusive tactics fit within the generic accepted "tough love." Tough love has a benign intention but does not distinguish from bullying and can include cruelty, malicious and humiliation. The researchers recommend open discussion and communication about what constitutes bullying [83].

The participants in this study described a variety of experiences from gossip to physical violence, yet all seemed unsure on how to define these experiences. The participants did not easily share their stories, and all shared their stories with some caution. Further, the participants seemed to seek validation from the researchers regarding their experiences and if their experiences were bullying. While both The Join Commission and the American Nursing Association have definitions of workplace bullying, none of the participants referred to these definitions. Rather, they each seemed to need a leader within their organization to support their perceptions of bullying. Could creating a clear definition of bullying within the industry of nursing for each organization support a common concept of acceptable and unacceptable professional conduct?

\section{Silencing}

Throughout the interviews, participants made statements, regarding the bullying experience like, Participant 03 sharing, "so I just left," or Participant 09 stating, "I just want to quit." These individuals feel that they are working in an environment that supports hostility and that they are expected to remain silent. Bullying is about power and control and making the victim feel powerless and weak. When we feel powerless and weak, we are ashamed and embarrassed. The shame is so intense, many will choose not to talk about it or even deny the experiences. While some feel pressure to accept the bullying to maintain order, others remain silent because they do not believe anyone will help or believe them. Szutenbach suggests that nurses can be intentionally socialized into not asserting themselves to combat bullying behavior and as a result allow it to continue and once silenced, the victims must conform or leave $[84,85]$. In a hospital setting, where nurses must think quickly, must make life or death decisions and must offer ongoing compassion to patients, shouldn't they have a voice? Aren't behaviors that result in the silencing of nurse, behaviors that ultimately damage the organization and go against the mission of health care?

But silencing is encouraged because it has positive outcomes for organizational leadership. Bullying and lateral violence is used as a method of disciplining the workforce to accept behaviors that maintain the status quo. Hutchinson, et al. assert that once there is quiet acquiescence in accepting these actions and practices as normalized, powerful actors can depend on others to ensure obedience [80]. Murray identified that in some organizations a 'wall of silence' is built to protect the bully, this can involve managers favoring people who behave in way that facilities and supports the bully [35].

\section{Peer Oppression}

"No one can be authentically human while he prevents others from being so," Paolo Freire (1921-1997) wrote the book, Pedagogy of the Oppressed- What Is It and Why It's Still Relevant. Dr. Freire introduces an approach to organizing to transform oppressive structures and create equality, care and beauty through action and reflection. He believes an organization of caring can exist even if the organization once experienced marginalization and dehumanization. Further, he discusses that bullying includes lateral violence, horizontal hostility, workplace violence, aggression, disrespect, hostility and incivility. Freire introduced the Pedagogy of the Oppressed as an education of the practice of freedom in contrast to an education as a practice of domination. How do these ideas translate to a health care setting? The same elements of oppression can be seen in health care institutions as evidenced by the experiences of the participants in this study. The participants state they were afraid to speak, had no one to turn to and had to remain silent about the bullying behaviors. Overall, Freire urges groups to strategize in the open with clear communication, clear agendas, organize with creative dialogue and participatory action, with these procedures, the goal is helping group members understand and recognize their own right to a worldview [75]. When nurses view themselves and the profession negatively, they develop a fatalistic acceptance 'that rejects evidence to the contrary in order to maintain and perpetuate the accepted myths' [86].

\section{Mission of the Nurse to Support Care is at Odds with the Mission of the Hospital to Profit}

Finally, having a continuous supply of registered nurses is crucial not only for healthcare organization finances but for the overall health of the US. "The country has experienced nursing shortages for decades, but an aging population means the probe is about to get much worse," [87]. If the mission of the hospital is to profit, isn't allowing unchecked bullying to continue a negative return on investment? Further, it is difficult to recruit nurses into an organization that has bullying tendencies [24]. How can the seemingly 
conflicting goals of profit and care be reconciled? It is not surprising that the costs of workplace bullying are estimated to be anywhere from $\$ 3$ billion to $\$ 36$ billion annually [88]. The hospitals must begin to address incivility in the workplace to maintain quality of care and maintain nurses in employment. The nursing shortage is at odds with the increasing health care needs in the United States. The gap between availability health care and health care need will only continue to grow with time Figure 3 (See Appendix).

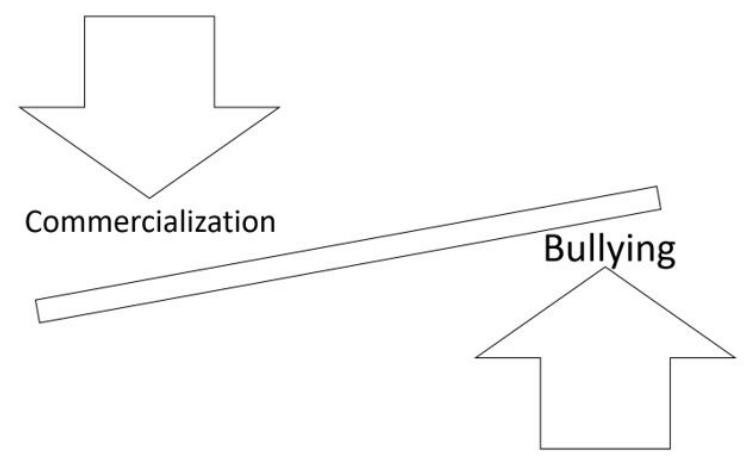

Figure 3: Study Theme Four: The Mission of the Nurse is at Odds with the Mission of the Hospital

\section{Contributions to the Literature}

The following study contributes to the broader literature on bullying by sharing the lived experiences of 12 nursing professionals. These individuals have unique experiences and they shared how they assigned meaning to their workplace bullying events. Through greater understanding of the stress and trauma experienced by bullying, it is hopeful that individuals and leadership in healthcare will choose to take a proactive approach to minimizing and eliminating bullying.

Further, the participants in this study effectively describe their thought process in choosing silence over action or reporting the bullying. The majority of the participant's felt they had only options of silence or leaving, none of the participants felt they had options of mediation or communication. None of the participants felt they had the power to end bullying in their organization.

\section{Limitation}

The study has a few limitations. All the participants were Caucasian, and it would be valuable to have greater diversity in the interview pool. Second, the interviews were opening ended and it could be helpful to pair the interviews with a survey that would allow for quantifying the participant's perceptions of workplace bullying. For example, a participant says a bullying experience was scary. It would be valuable to know how scary the participant perceives the event on a scale of 1-10.

\section{Conclusion}

The study sought to understand two questions, one, Do nursing professionals experience bullying in the workplace? and two, How does bullying behavior impact the nurse's responsibilities? All thirteen nursing participants describe either directly experiencing bullying in their health care related profession or observing bullying in their health care related profession. All twelve nursing participants describe personal negative outcomes by experiencing or observing bullying in their workplace aligned with the literature review as outlined in Table 3 (See Appendix). The negative outcomes included increased stress, sadness, frustration and considerations or leaving the job or the profession. Bullying has been studied for 20 years and some of the remedies that have been implemented have been education, in-service training and discussions with nursing students. Should something more proactive be done? Something like itemizing the nurse's contribution on the bill or including personality assessments targeting bullying behaviors be included in the hiring process? While the exact solution is unknown, it is certain that ignoring bullying and considering the issue a back-burner issue will not bring about change. Rather, bullying in the nursing culture must be recognized not only by hospital leadership but by the nursing community as a front burner issue. Change must occur beginning in the nursing classrooms and continue with hospital leadership.

\section{References}

1. Bureau of Labor Statistics (April, 2018) (2018) Registered Nurses.

2. KFF (2018) Hospitals Step Up Recruitment Efforts to Address Nursing Shortage. AACN Bold Voices 10: 20.

3. MacKusick CI, Minich P (2010) Why are nurses leaving? Findings from an initial qualitative study on nursing attrition. MedSurg Nurs 19: 335-40.

4. Bandura A (1977) Social Learning theory. Engelwood Cliffs, NJ Prentice-Hall 247.

5. Olweus D (1993) Bullying at school: What we know and what we can do. Oxford, England, Blackwell 140.

6. Thompson R, George LE (2016) Preparing New Nurses to Address Bullying: The Effect of an Online Educational Module on Learner Self-Efficacy. Medsurg Nurs 25: 412-7.

7. Dessler G (2013) Fundamentals of human resource management. New York. 
8. Pheko M (2018) Rumors and gossip as tools of social undermining and social dominance in workplace bullying and mobbing practices: A closer look at perceived perpetrator motives. J Human Behav Soc Environ 28: 449-65.

9. Granstra K (2015) Nurse Against Nurse: Horizontal Bullying in the Nursing Profession. J Healthcare Manag 60: 249-57.

10. Courtney-Pratt H, Pich J, Levett-Jones T, Moxey A (2018) “I was yelled at, intimidated and treated unfairly": Nursing students' experiences of being bullied in clinical and academic settings. J Clin Nurs 27: E903-E912.

11. Clarke CM, Kane DJ, Rajacich DL, Lafreniere KD (2012) Bullying in Undergraduate Clinical Nursing Education. J Nurs Educ 51: 269-76.

12. Berry PA, Gillespie GL, Gates D, Schafer J (2012) Novice nurse productivity following workplace bullying. J Nurs Scholarsh, 44: 80-7.

13. Occupational Safety and Health Administration (2015) Workplace violence in health care: Understanding the challenge. OSHA 3826, $12 / 2105$.

14. Laschinger HK, Grau AL, Finegan J, WilkP (2010) New graduate nurses' experiences of bullying and burnout in hospital settings. J Adv Nurs 66: $2732-42$.

15. Lavoie-Tremblay M, Paquet M, Marchionni C, Drevniuk U (2011) Turnover intention among new nurses. A generational perspective. J Nurs Staff Dev 27: $39-45$.

16. Weaver KB (2013) The effects of horizontal violence and bullying on new nurse retention. J Nurse Prof Dev 29: 138-42.

17. Starr L (2017) Good from Evil: Violence in the workplace is a hazard and risks the health and safety of all those working in that environment. Aust Midwifery J 25: 28 .

18. Cleary M, Hunt GE, Horsfall J (2010) Identifying and addressing bullying in nursing. Issues Ment Health Nurs, 31: 331-5.

19. Sauer P, McCoy T (2016) Nurse bullying: Impact on nurses' health. West J Nurs Res 39: 1533-46.

20. Laws L (2016) Bullying in the workplace. Texas Board Nurs Bull 47: 4.

21. Krugman M, Heggem L, Kinney L, Frueh M (2013) Longitudinal charge nurse leadership development and evaluation. J Nurs Adm 43: 438-46.

22. RSA (2014) HRSA report on nursing workforce projections through 2025. Am Assoc Coll Nurs.

23. American Association of Colleges of Nursing (2014) Nursing shortage.

24. Townsend T (2016) Not just "eating our young": Workplace bullying strikes experienced nurses, too. Am Nurse Today 11.

25. Wood D (2013) HRSA reports on nursing supply and education trends. Healthcare News.

26. Snavely TM (2016) A brief economic analysis of the looming nursing shortage in the United States. Nurs Econo 34: 98-100.

27. Miller-Hoover S (2016) Incivility in healthcare: How we can change the culture. RN.Com.

28. Edmondson C (2017) How to recognize and prevent bullying in nursing. Nurse.com.

29. Ovayolu O, Ovayolu N, Karadag G (2014) Workplace bullying in nursing. Workplace Health Saf, 62: 370-4.

30. Hoban V (2004) Bullying and nursing. Nurs Times, 100: 16-8.

31. Farrell, Shafiei (2012) Workplace aggression, including bullying in nursing and midwifery: A descriptive survey (the SWAB study). Int J Nurs Stud 49:1423-31.

32. Lowenstein L (2013) Bullying in nursing and ways of dealing with it. Nurs Times 109: 22-5.

33. Harris H, Smith CJ (2014) Nurse bullying in the workplace. Adv Healthcare Network.

34. Burkley J (2018) Adopt Zero Tolerance for Hospital Staff Bullying Nursing Students. AJN 118: 11.

35. Murray JS(2009) Workplace bullying in nursing: A problem that can’t be ignored. MedSurg Nurs, 18: 273-6.

36. Spence Laschinger H, Nosko A (2015) Exposure to workplace bullying and post-traumatic stress disorder symptomology: The role of protective psychological resources. J Nurs Manag, 23: 252-62.

37. Butler E, Prentiss A, Benamor F (2018) Exploring perceptions of workplace bullying in nursing. Nurs Health Sci Res J 1:19-25.

38. Ruler A (2015) Bullying, relational aggression and nursing. Aust Nurs Midwife J 23: 35.

39. Olweus D (2016) Recognizing bullying. Violence Prev Works! Safer Schools, Safer Communities.

40. Workplace Bullying Institute (2013) Bullying is workplace violence.

41. Bazelon E (2013) How do we define bullying. Psychol Today.

42. Thompson R (2017) Three strategies to tackle a bullying boss. Transforming Healthcare Edu.

43. Birks M, Budden L, Biedermann N, Park R, Chapman Y (2018) A 'rite of passage?'; Bullying experiences of nursing students in Australia. Collegian 25: 45-50.

44. D’Souza N, Forsyth D, Tappin D, Catley B (2018) Conceptualizing workplace cyberbullying: Toward a definition for research and practice in nursing. J Nurs Manag 26: 842-50.

45. Stagg S, Sheridan D, Jones R, Speroni K (2013) Workplace bullying: The effectiveness of a workplace program. Workplace Health Saf 61: 333- 8 .

46. Bloom E (2014) Horizontal Violence Among Nurses: Experiences, Responses and Job Performance. Rhode Island, Univ Rhode Isl.

47. Johnson S, Rea R (2009) Workplace bullying: Concerns for nurse leaders. J Nurs Adm 39: 84-90.

48. Handzel S (2017) Zero tolerance: Stopping nurse bullying begins with leadership. Oncol Nurs News.

49. Waschgler K, Antonio J, Ruiz-Hernandez J, Llor-Esteban B, Jimenez-Barbero J (2013). Vertical and lateral workplace bullying in nursing: Development of the hospital aggressive behavior scale. Journal of Interpersonal Violence, 28: 2389-412.

50. Giorgi G (2016) Bullying among nurses and its relationship with burnout and organizational climate. Intern J Nurs Pract 22.

51. Manton A (2017) Bullying: A Pebble in the Pond. J Emergency Nurs 43: 389-90.

52. Gillespie GL, Grubb PL, Brown K, Boesch MC, Ulrich D (2017) “Nurses Eat Their Young”: A Novel Bullying Educational Program for Student Nurses. J Nurs Educ Pract 7: 11-21.

53. Bambi S, Guazzini A, Piredda M, Lucchini A, De Marinis M, et al. (2018) Negative interactions among nurses. An explorative study on lateral violence and bullying in nursing work settings. J Nurs Manag.

54. Solheim J (2018) Caring for each other while we care for others. J Emergency Nurs 44: 319-20.

55. Gaffney D, DeMarco R, Hofmeyer A, Vessey J, Budin W (2012) Making Things Right: Nurses' Experiences with Workplace Bullying-A Grounded Theory. Nurs Res Pract 2012:10.

56. Thompson R (2015) “Replace our culture of silence with one of safety". Nurs Times 111: 11.

57. Wilson J (2016) An exploration of bullying behaviours in nursing: A review of the literature. Br J Nurs 25: 303-6. 
58. Croft K, Croft A (2012) Deconstructing contributing factors to bullying and lateral violence in nursing using a postcolonial feminist lens. Contemp Nurse, 42: 226-42.

59. Purpora C, Blegen M, Stotts N (2012) Horizontal violence among hospital staff nurses related to oppressed self or oppressed group. J Prof Nurs, 28 : 306-14.

60. Ogle K, Glass N (2014) Nurses' Experiences of Managing and Management in a Critical Care Unit. Glob Qual Nurs Res 1: 2333393614532617.

61. Glass N (1998) Becoming de-silenced and reclaiming voice: Women nurses speak out. School Health Human Sci 121-38.

62. Rodwell J, Demir D (2012) Oppression and exposure as differentiating predictors of types of workplace violence for nurses. J Clin Nurs 21: $2296-305$.

63. NSI (2016) 2016 National Healthcare Retention \& RN Staffing Report. Nurs Solutions Inc.

64. Johnson N (2015) Why good nurses leave the profession. Minority Nurse.

65. Fink-Samnick E (2018) The side effects of workplace bullying in healthcare. ICD10Monitor.

66. Hutton S, Gates D (2008) Workplace incivility and productivity losses among direct care staff. AAOHN 56: 168-75.

67. Two-thirds of nurses consider quitting due to stress, says RCN (2013) Nurs Times.

68. James J (2013) A new, evidence-based estimate of patient harms associated with hospital care. J Patient Saf 9: 122-8.

69. Andel C, Davidow S, Hollander M, Moreno D (2012) The economics of health care quality and medical errors. J Health Care Finance 39: 39-50.

70. Kumar S, Mckewan G (2011) Six Sigma DMAIC Quality Study: Expanded Nurse Practitioner's Role in Health Care During and Posthospitalization Within the United States. Home Health Care Manag Pract, 23: 271-82.

71. Andrea C, Velasquez M (2015) A healthy bottom line: Profits or people? Markkula Center Appl Ethics.

72. Brody H (2014) Economism and the Commercialization of Health Care. The J Law Med Ethics 42: 501-8.

73. Grimm J (2015) Workplace bullying: It’s costs and prevention. Employment Essentials.

74. Giorgi A (1970) Psychology as a Human Science. N York, Harper and Row.

75. Willis P (2004) From “The things themselves" to a "Feeling of understanding”: Finding different voices in phenomenological research. Indo-Pac J Phenomenol 4: 1-13.

76. Lloyd GM, Sailor JL, Carney W (2014) A phenomenological study of post-divorce adjustment in midlife. J Divorce and Remarriage 55: 441-50.

77. Flynn S, Korcuska J (2018) Credible phenomenological research: A mixed-methods study. Couns Edu Supervision.

78. Dukes S (1984) Phenomenological methodology in the human sciences. J Religion Health 23: 197-203.

79. Moustakas C (1994) Phenomenological research methods. Thousand Oaks, California.

80. Freire P (2014) “Pedagogy of the Oppressed: 30th Anniversary Edition.” Bloomsbury Publishing USA.

81. May D, Grubbs L (2002) The extent, nature, and precipitating factors of nurse assault among three groups of registered nurses in a regional medical center. J Emerg Nurs 28: 11-7.

82. Brooks, Bosk (2013) Bullying is a systems problem. Soc Sci Med 77: 11-12.

83. Leong Y, Crossman J (2016) Tough love or bullying? New nurse transitional experiences. J Clin Nurs 25:1356-66.

84. Szutenbach M (2013) Bullying in nursing: roots, rationales and remedies. J Christ Nurs 30: 16-23.

85. Hutchinson M, Vickers M, Jackson D, Wilkes L (2010) Bullying as circuits of power: An Australian perspective. Administrative Theory Praxis 32: 25-47.

86. Street A (1990) Nursing practice: High, hard ground, messy swamps and the pathways in between. Geelong, VIC, Deakin Univ Press 34.

87. Grant R (2016) The U.S. is running out of nurses. The Atlantic.

88. Olender-Russo L (2009) Creating c culture of regard: an antidote for workplace bullying. Creat Nurs, 15: 75-81.

89. Bazelon E (2013) How do we define bullying. Psychol Today.

90. Gaffney D, DeMarco R, Hofmeyer A, Vessey J, Budin W (2012) Making Things Right: Nurses' Experiences with Workplace Bullying-A Grounded Theory. Nurs Res Pract 2012:10. 